\title{
A Three-Layer Thermodynamic Model for Ice Crystal Accretion on Warm Surfaces: EMM-C
}

\author{
Author, co-author (Do NOT enter this information. It will be pulled from participant tab in \\ MyTechZone) \\ Affiliation (Do NOT enter this information. It will be pulled from participant tab in MyTechZone)
}

\begin{abstract}
Ingestion of high altitude atmospheric ice particles can be hazardous to gas turbine engines in flight. Ice accretion may occur in the core compression system, leading to blockage of the core gas path, blade damage and/or flameout. Numerous engine powerloss events since 1990 have been attributed to this mechanism. An expansion in engine certification requirements to incorporate ice crystal conditions has spurred efforts to develop analytical models for phenomenon, as a method of demonstrating safe operation. A necessary component of a complete analytical icing model is a thermodynamic accretion model. Continuity and energy balances are performed using the local flow conditions and the mass fluxes of ice and water that are incident on a surface to predict the accretion growth rate. In this paper, a new thermodynamic model for ice crystal accretion is developed through adaptation of the Extended Messinger Model (EMM) from supercooled water conditions to mixed phase conditions (ice crystal and supercooled water). A novel three-layer accretion structure is proposed and the underlying equations described. The EMM improves upon the original model for airframe icing, the Messinger Model, by permitting a linear temperature gradient through the ice and water layers. This in turn allows prediction of the time over which water exists in isolation on an initially warm surface, before an ice layer forms. This is of particular interest to engine icing, as surfaces may initially be significantly above freezing temperature, before cooling on exposure to ice particles. The method is solved in a multi-step approach, where the overall exposure time is divided into discrete windows, and the calculation performed over each window. This allows the local flow conditions to be updated between windows, permitting the incorporation of a reducing flow enthalpy due to particle evaporation, as well as transient engine operation. Model results are then compared to experimental results. Comparisons are made to solutions generated using the standard Messinger Model.
\end{abstract}

\section{Introduction}

In recent years it has been assessed that numerous engine power loss events at high altitudes can be attributed to ice crystal accretion in the core compression system [1]. These events were assessed to occur at altitudes exceeding $22,000 \mathrm{ft}(\sim 6700 \mathrm{~m})$, the accepted upper limit for the existence of water in supercooled liquid form. Ice particles may be present in concentrations exceeding $2 \mathrm{~g} / \mathrm{m}^{3}$ in the anvil region of tropical storms (reaching up to 60,000 feet at the equator), or may co-exist with supercooled water at lower altitudes. It is theorized that, if ingested into the core compression system, particles may exchange heat with engine surfaces and the airflow; melting, evaporating and sublimating. This continues until conditions are sufficiently cold to permit refreezing and accretion. In small engines - for business and narrow body aircraft aerodynamic blockage of the core may lead to uncommanded loss of thrust (rollback). In larger engines, shedding of accretions may lead to compressor damage, surge and/or flameout.

A new envelope for certifying engines in ice crystal conditions was first proposed by the Engine Harmonization Working Group (EHWG) in 2005, based on data from over 60 known engine power Page 1 of 11 loss events. The envelope was subsequently adopted by regulatory authorities, leading to renewed efforts by engine OEMs to develop acceptable means of compliance. Semi-empirical models have been assessed as a cost-effective method, since whole-engine tests simulating both altitude and atmospheric ice particles - is currently not possible for civil aircraft engines with intakes greater than around $2 \mathrm{~m}$ diameter. Flight tests are possible but the conditions at which accretion occurs is unlikely to be encountered repeatably or measured easily.

Existing analytical models for icing have primarily been confined to supercooled water icing, under which water droplets impinge on sub-freezing engine or airframe components [2], [3]. These codes rely on a thermodynamic model to predict ice accretion following a flowfield solver and particle tracking. Ice crystal accretion has been treated more simply as a continuity-based approach [4] if a sticking fraction at a given thermodynamic condition is known. The limitation of this approach is apparent - sticking fractions must be known empirically for every condition of interest and thus is rather inflexible. Given the current dearth of experimental data for ice crystal icing, the range of conditions for which this information is known to a good degree of accuracy is small. In contrast, a thermodynamic approach provides a mechanism for modelling the necessary physical processes (evaporation, melting, runback etc.) at any condition. It also permits transient behaviour to be modelled for example the temperature response of the underlying component. It is therefore necessary to consider how existing thermodynamic models for supercooled water icing may be adapted to ice crystal icing.

Messinger [5] first formalised a thermodynamic accretion model for supercooled liquid droplets impinging on the wings of aircraft. This model still forms the basis of the most widely used icing codes today [6]. It is a steady approach that assumes that the component surface (substrate) immediately adopts its equilibrium temperature, and holds it for the whole simulation time. Heat transfer normal to the surface is neglected (i.e. the accretion is at a uniform steady temperature). The equilibrium temperature is calculated using an energy balance which considers evaporation, convection, melting, sensible warming of impinging droplets, and transfer of kinetic energy from impinging droplets. The Messinger model has been implemented in the first generation of ice crystal icing codes, for both non-porous ([3], [7]) and porous ([8]) accretions. It has also been used in cases where unsteady heating from an anti-icing or deicing system is modelled; in this case a three-layer (water-ice-water) model may occur [9].

Myers [10] proposed an improvement to the Messinger model, termed the 'Extended Messinger Model' (EMM). This model permits a linear temperature gradient normal to the icing surface, and thus heat flux from the substrate through the water and ice layers. This approach is therefore quasi-steady: time enters the problem through the changing accretion height - which due to the temperature gradient therefore produces a changing accretion surface temperature. Moreover, the EMM predicts the time over which a water layer exists in isolation, before any ice layer forms. Özgen and Canibek [11] further added to the temporal dependency 
by growing the accretion over multiple steps. For each step, the EMM is solved and the ice and water layers grown. After each step, particle collection efficiency is updated. It may also be possible for the flowfield to be updated for further improvement in accuracy. Performing a multiple step model also permits the incorporation of transient flow conditions as parameters may be updated between each layer calculation. This is of importance to engine icing since it is known that enthalpy exchange between particles and the warm airflow may lead to an appreciable reduction in the temperature profile through the compressor over the exposure time [12]. This reduction may be calculated a-priori by implementing two-way coupling of energy [13].

More recently, Ayan and Özgen [14] presented additional terms to adapt the Extended Messinger Model to mixed phase and glaciated conditions, and applied it to engine intakes and pitot tubes [15]. However, similarly to the Messinger and Extended Messinger models, it is only directly applicable for sub-freezing substrates (and usually, therefore, for sub-freezing total temperatures). This is incompatible with the accepted theory that accretion in the engine core is a direct consequence of warmer-than-freezing temperatures. In this paper, a new adaptation of the Extended Messinger Model (EMM) is presented, for use in glaciated and mixed phase conditions. The novel three-layer approach allows the substrate onto which the ice grows to be initially above or below freezing temperature. This is a critical step in modelling ice crystal icing in an engine core, as opposed to external airframe surfaces, engine inlets or pitot tubes.

\section{The Extended Messinger Model}

Fig. 1 shows the assumed form of the liquid water droplet icing problem. An ice layer forms first as the droplets impact and freeze on the substrate. The ice layer has thickness $B(t)$ and temperature profile $T(z, t)$. Energy is released, proportional to the latent heat of fusion, as the ice layer grows. This is summed with the other heat fluxes at the surface (evaporation, convection etc.). The sign and magnitude of this summation will determine whether the exposed surface will reach $0{ }^{\circ} \mathrm{C}$, allowing a water film to form on top. In the EMM, the water film thickness is given by $h(t)$ and temperature profile by $\theta(z, t)$. The nomenclature used here will be retained when adapted to ice crystal icing.

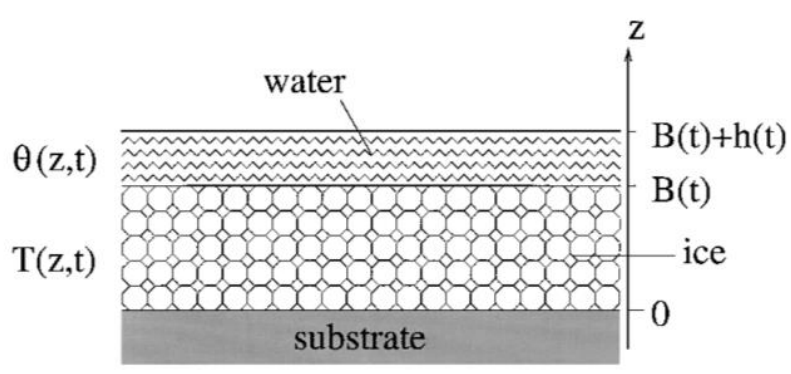

Fig. 1 Assumed form of supercooled water icing problem in original Extended Messinger Model [10]

The four equations describing the problem comprise continuity (equation 1), one dimensional heat equations in the ice and water layers (equations 2 and 3) and an energy balance (equation 4) at the ice-water interface. The latter states that the imbalance between the rate of heat conduction in the ice layer and water layer determines the heat of fusion available at the interface, and hence the freezing rate.

$$
\rho_{w} \frac{d h}{d t}+\rho_{i} \frac{d B}{d t}=\dot{m}_{s t u c k}+\dot{m}_{r u n, i n}-\dot{m}_{e, s}
$$

$$
\begin{gathered}
\frac{\partial^{2} \theta}{\partial z^{2}}=\frac{C_{p, w} \rho_{w}}{k_{w}} \frac{\partial \theta}{\partial t} \\
\frac{\partial^{2} T}{\partial z^{2}}=\frac{C_{p, i} \rho_{i}}{k_{i}} \frac{\partial T}{\partial t} \\
\rho_{i} L_{f} \frac{d B}{d t}=-k_{w} \frac{\partial \theta}{\partial z}+k_{i} \frac{\partial T}{\partial z}
\end{gathered}
$$

where $\dot{m}_{\text {stuck }}$ is the mass flux of droplets sticking on the surface; $\dot{m}_{\text {run,in }}$ is the mass flux of water running into the domain from an upstream domain (this term is zero if the problem is framed in 1D); and $\dot{m}_{e, s}$ is the mass flux leaving the exposed accretion surface by evaporation or sublimation.

\section{Model Assumptions}

The primary assumptions in the original EMM are:

(A1) Lateral conduction is neglected; only water runback may transfer enthalpy laterally for two- or three-dimensional problems;

(A2) The temporal derivative of the ice and water temperatures may be neglected. The heat equations are then simplified to

$$
\frac{\partial^{2} \theta}{\partial z^{2}}=\frac{\partial^{2} T}{\partial z^{2}}=0
$$

The problem is therefore reduced to quasi-steady one-dimensional conduction, where time enters the problem via the changing ice and water layer thicknesses. Physically this implies that advective transport due to the accretion growth has a significantly longer timescale than the thermal diffusivity $(\alpha)$. The validity of this assumption may be assured if the Péclet number is significantly below unity, defined as

$$
P e=\frac{\text { advective transport rate }}{\text { thermal diffusivity in ice }}=\frac{U L}{\alpha_{i}}=\frac{\dot{h} L \rho_{i} C_{p, i}}{k_{i}}
$$

where $U$, the velocity, is taken as the accretion growth rate $\dot{h}$. Using typical value from previous experiments in crystal test facilities results in $P e \cong 0.5$ [16]. This shows that the validity of the assumption in ice crystal icing conditions is marginal - compared to supercooled water icing where the growth rate, $\dot{h}$, is typically significantly lower [10]. Adaptation of the method to unsteady heat conduction is outside of the scope of the current work, but has been studied recently by Chauvin et al [9], with application to supercooled water icing.

(A3) There is perfect thermal contact between the accretion and substrate. The substrate may have a constant or time-varying temperature

$$
T(z=0, t)=T_{\text {subs }}(t)
$$

(A4) The temperature at the ice-water interface is equal to the freezing temperature

$$
T(z=h, t)=T_{f}
$$

(A5) At the exposed accretion surface, the following energy sources and sinks are considered: convection, evaporation or sublimation, kinetic energy transfer from impinging droplets, latent heat of fusion, aerodynamic heating, sensible warming of impinging droplets and sensible warming of incoming runback water. Radiation is neglected. One-dimensional conduction within the 
substrate is neglected or included via an imposed temperature boundary condition.

\section{EMM-C Model Proposition}

In this section, the approach and equations for adapting the EMM to ice crystal icing are presented. The new model is hereon referred to as EMM-Crystals, or EMM-C. The necessary adaptations comprise:

1. Permitting the substrate to be either initially above or below freezing temperature;

2. Permitting the impinging mass flux to be fully glaciated, mixed phase or fully liquid.

In the following derivation, calculations are performed in one dimension for a single surface panel. For cases where a water film forms, the 'gross' film height is calculated first (neglecting run out water). After the thermodynamic analysis has been performed, runback water out of the domain is then calculated. It is assumed to run axially downstream, as shown in Fig. 2.

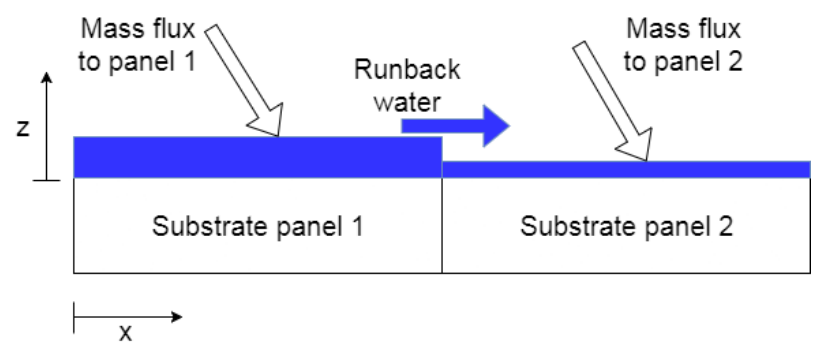

Fig. 2 Schematic of runback water between axially adjacent panels

Time stepping is performed in pseudo-time. In each timestep, panels are marched through sequentially, after which layer thicknesses and temperature profiles are updated. Aerodynamic and icing conditions may be varied between timesteps.

Two separate solution routes must be considered depending on whether the clean substrate is above or below freezing, as shown in Fig. 3. This determines whether the first impinging particles will melt, forming a water layer, or freeze, forming an ice layer. The assumed situations for either scenario are shown in Fig. 4.

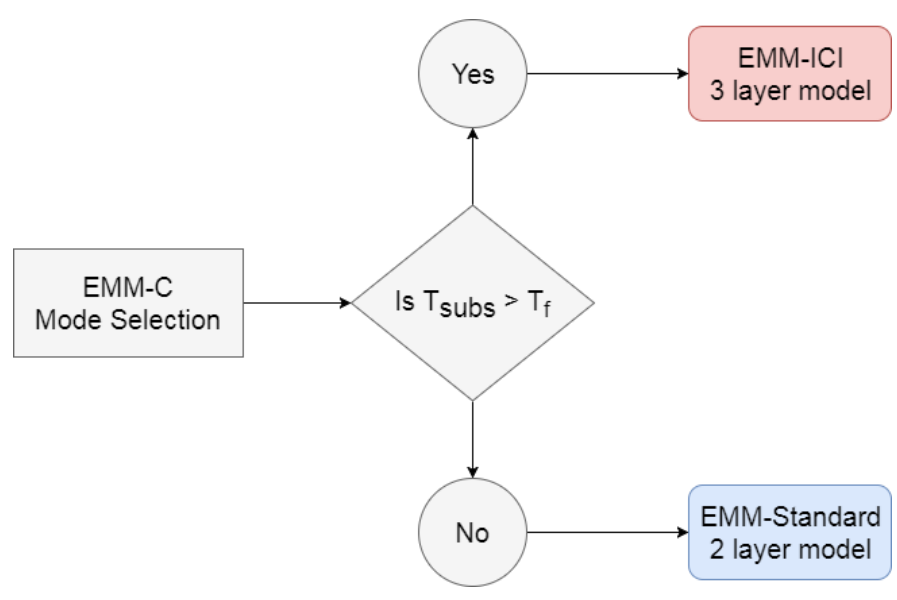

Fig. 3 Model selection within EMM-C based on initial substrate temperature

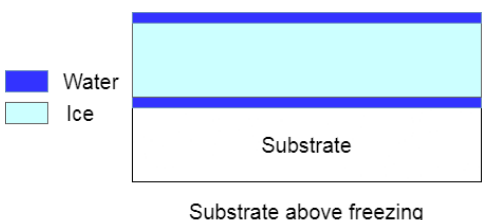

Substrate above freezing

EMM-ICl (3 layer model)

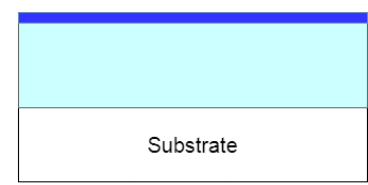

Substrate below freezing EMM-Standard (2 layer model)

Fig. 4 Assumed form of the ice crystal icing problem for a substrate above freezing (left) and below freezing (right).

The case of a substrate initially below freezing is essentially the same as the original EMM, albeit adapted to glaciated and mixed phase conditions. A suitable model is presented in Ayan \& Özgen [14]. The case of a substrate initially above freezing temperature is now considered in detail.

\section{EMM-C Model Derivation}

The case of an initially warm substrate should be considered in two distinct stages; in the first, the mixed phase impinges on the surface, melts and forms a water layer. If the latent heat of fusion absorbed in the melting process is not balanced by other energy sources, heat is lost from the system and at some time the water surface temperature will fall to freezing temperature, permitting the formation of an ice layer (stage two).

\section{Stage 1 - Water Layer}

Fig. 5 shows a schematic of the initial water film, with fluxes of heat and mass.

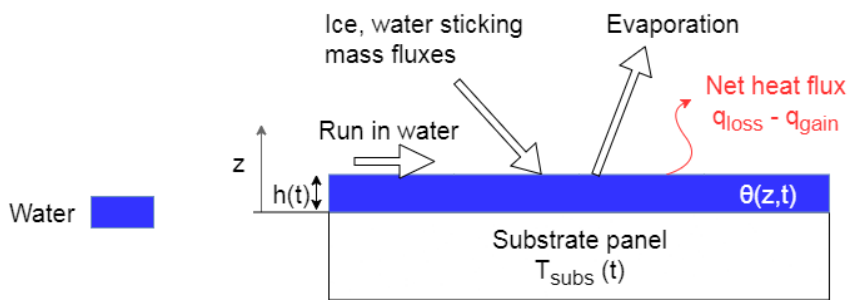

Fig. 5 Schematic of stage 1 (water film) with fluxes of heat and mass

Since all of the impinging mass flux is assumed to melt, the water layer height is solved directly from continuity (equation (1)), with $d B / d t=0$

$$
h=\frac{1}{\rho_{w}}\left(\dot{m}_{\text {stick }, i}+\dot{m}_{\text {stick,w }}+\dot{m}_{\text {run,in }}-\dot{m}_{\text {evap }}\right) t
$$

The temperature profile through the water layer at a given timestep may now be solved. Starting from the quasi-steady assumption, the one-dimensional heat equation for the water layer is

$$
\frac{\partial^{2} \theta}{\partial z^{2}}=0
$$

The net heat flux through the exposed water surface may be used as a boundary condition, applied at $z=h$ :

$$
\begin{aligned}
-k_{w} \frac{\partial \theta}{\partial z}=q_{\text {loss }}- & q_{\text {gain }} \\
& =\left(q_{\text {conv }}+q_{\text {evap }}+q_{\text {sens,imp }}\right. \\
& \left.+q_{\text {sens,run }}\right)-\left(q_{\text {kin }}+q_{\text {freeze }}\right)
\end{aligned}
$$

where 


$$
\begin{aligned}
& q_{\text {conv }}=H\left(\theta_{h}-T_{r}\right) \\
& q_{\text {evap }} \cong \frac{L_{v} H}{P_{0} C_{p, a} L e^{1-b}} \frac{M_{w}}{M_{a}}\left(P_{\text {vap }, \text { surf }}-P_{\text {vap }, \infty}\right) \\
& q_{\text {sens,imp }}=\dot{m}_{\text {stick,i }} C_{p, i}\left(T_{f}-T_{p, i}\right) \\
& +\dot{m}_{\text {stick }, i} C_{p, w}\left(\theta_{h}-T_{f}\right) \\
& +\dot{m}_{\text {stick,w }} C_{p, w}\left(\theta_{h}-T_{p, w}\right) \\
& q_{\text {sens,run }}=\dot{m}_{\text {run,w }} C_{p, w}\left(\theta_{h}-T_{\text {run }}\right) \\
& q_{k i n}=1 / 2\left(\dot{m}_{s t i c k, i}+\dot{m}_{s t i c k, w}\right){\overline{U_{p}}}^{2} \\
& q_{\text {freeze }}=-L_{f} \dot{m}_{\text {stick }, i}
\end{aligned}
$$

where $\theta_{h}$ is the temperature of the water at the exposed surface, $T_{r}$ is the surface recovery temperature, and $H$ is the heat transfer coefficient. A derivation of the evaporative heat flux (equation 13) is given in Appendix A. The runback water temperature, $T_{\text {run }}$, is the average water temperature of the upstream panel. $\overline{U_{p}}$ is the average velocity of particles (water and ice) impinging on the panel in question.

$P_{\text {vap }, \text { surf }}$ and $P_{\text {vap, } \infty}$ are the water vapour pressures at the accretion surface and in the freestream respectively. These in turn requires evaluation of the saturation vapour pressures at these locations (a function of the local temperature). Saturation vapour pressure may be calculated from an empirical formula such as that of Hyland and Wexler (1983). In the Extended Messinger Model [10] saturation vapour pressure is approximated as a linear function over the range $257 \leq T(\mathrm{~K}) \leq T_{f}$. This approach is maintained in the current work, however it is modified to a piecewise linear approximation over an extended range of applicability. This is necessitated by the adaptation of the model to ice crystal icing, where temperatures may be significantly above freezing as well as below. A 19-segment piecewise linear fit is used instead, applicable over the range $245 \leq$ $T(K) \leq 320$, given in Appendix B. Equation (13) is then expressed as

$$
q_{\text {evap }} \cong C_{1}\left[\left(E_{m 1} \theta_{h}+E_{c 1}\right)-R H_{\infty}\left(E_{m 2} T_{a}+E_{c 2}\right)\right]
$$

where $E_{m 1}, E_{c 1}$ are the gradient and y-intercept of the piecewise linear fit of saturation vapour pressure, evaluated at the accretion surface temperature $\theta_{h} ; E_{m 2}, E_{c 2}$ are the equivalent values evaluated at the air static temperature $T_{a}$. The constant $C_{1}$ is given by

$$
C_{1} \cong \frac{L_{v} H}{P_{0} C_{p, a} L e^{1-b}} \frac{M_{w}}{M_{a}}
$$

Equation (10) may be integrated twice using the boundary conditions in equations (11) and (7) to obtain the temperature in the water layer:

$$
\theta=\frac{q_{2}-q_{1} T_{\text {subs }}}{k_{w}+h q_{1}} z+T_{\text {subs }}
$$

where

$$
\begin{aligned}
q_{1}=H+C_{1} E_{m 1}+ & \dot{m}_{\text {stick }, i} C_{p, w}+\dot{m}_{s t i c k, w} C_{p, w} \\
& +\dot{m}_{\text {run }, w} C_{p, w}
\end{aligned}
$$

$$
\begin{aligned}
q_{2}=1 / 2\left(\dot{m}_{s t i c k, i}\right. & \left.+\dot{m}_{\text {stick }, w}\right){\overline{U_{p}}}^{2} \\
& -\left[C _ { 1 } \left(-R H_{\infty}\left(E_{m 2} T_{a}+E_{c 2}\right)\right.\right. \\
& \left.+E_{c 1}\right)+L_{f} \dot{m}_{s t i c k, i}-H T_{r} \\
& +\dot{m}_{\text {stick }, i} C_{p, i}\left(T_{f}-T_{p, i}\right) \\
& -\dot{m}_{\text {stick }, i} C_{p, w} T_{f}-\dot{m}_{s t i c k, w} C_{p, w} T_{p, w} \\
& \left.-\dot{m}_{r u n, w} C_{p, w} T_{r u n}\right]
\end{aligned}
$$

The calculation continues until either (i) the temperature of the exposed water surface falls to freezing, i.e. $\theta(h, t)=T_{f}$, or (ii) the surface temperature remains above freezing for the entire calculation time (running wet conditions prevail). If the first scenario occurs, the calculation moves to the second stage.

\section{Stage 2 - Three-Layer Model}

In the second stage, an ice layer is assumed to form over the initial water film. A surface water film may also form on top of the ice layer if there is sufficient energy at the exposed surface, producing a three layer system. This is illustrated in Fig. 6.

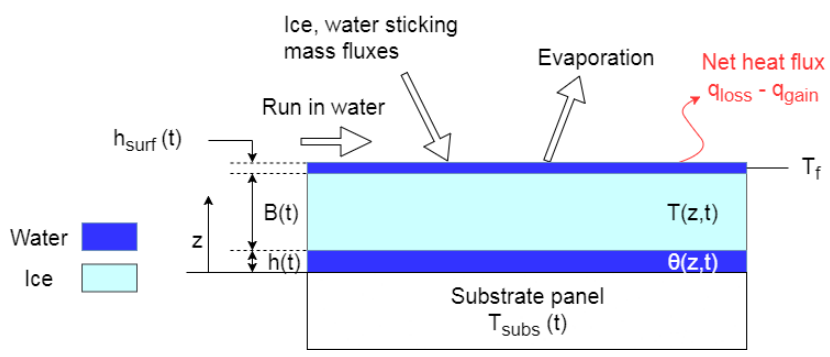

Fig. 6 Schematic of stage 2 (three layer model) with fluxes of heat and mass

The presence of an internal water layer is a necessary result of assumption (A3); whilst the substrate temperature remains above freezing, the layer directly above must be liquid. The layer is assumed to be 'trapped' - i.e. it may not flow axially.

In the first stage, the heat transfer due to particle melting is known a-priori, since it is inherently assumed in this stage that all ice must melt. This is not the case in the second stage; the amount of refreezing or melting of the impinging mixed phase flux is unknown. An additional equation is therefore required to close the problem:

(A6) The surface water film is sufficiently thin that wall-normal temperature gradients may be neglected. Since the temperature at the water-ice interface must be at the freezing temperature $T_{f}$, it is therefore taken that the whole film is at this temperature.

$$
\theta_{\text {surf }}(z, t)=T_{f}
$$

The heat and energy equations in the internal water layer and ice layer are given by

$$
\begin{gathered}
\frac{\partial^{2} \theta}{\partial z^{2}}=\frac{\partial^{2} T}{\partial z^{2}}=0 \\
\rho_{w} L_{f} \frac{d h}{d t}=-k_{w} \frac{\partial \theta}{\partial z}+k_{i} \frac{\partial T}{\partial z}
\end{gathered}
$$

The heat equations may be integrated simply:

$$
\theta=\frac{T_{f}-T_{\text {subs }}}{h} z+T_{\text {subs }} \quad ; \quad T=T_{f}
$$




$$
\frac{d h}{d t}=\frac{1}{\rho_{w} L_{f}}\left(-k_{w} \frac{T_{f}-T_{\text {subs }}}{h}\right)
$$

It is instructive at this point to isolate the two contributions to the growth of the ice layer: from (i) the freezing or melting at the internal water layer interface and (ii) freezing or melting of the surface water film. This is given by equation (28):

$$
\frac{d B}{d t}=\frac{d B_{\text {int }}}{d t}+\frac{d B_{\text {surf }}}{d t}
$$

where

$$
\frac{d B_{i n t}}{d t}=-\frac{\rho_{w}}{\rho_{i}} \frac{d h}{d t}
$$

since any ice growth at the internal interface is matched by a reduction in the internal water layer.

The continuity equation for water at the top surface is given by

$$
\rho_{w} \frac{d h_{\text {surf }}}{d t}=\dot{m}_{s t u c k, w}+\dot{m}_{\text {run }, \text { in }}-\dot{m}_{\text {evap }}-\dot{m}_{f}
$$

where $\dot{m}_{f}$ is the mass flux freezing at the top surface. The corresponding equation for surface ice growth is

$$
\frac{d B_{\text {surf }}}{d t}=\dot{m}_{\text {stuck,i }}+\dot{m}_{f}
$$

It then remains to find $\dot{m}_{f}$. Similarly to the water-only first stage, the net surface heat flux may be used as a boundary condition, except applying assumption (A6) requires the net flux to be zero.

$$
\begin{aligned}
& q_{\text {loss }}-q_{\text {gain }}=q_{\text {net }} \\
& =\left(q_{\text {conv }}+q_{\text {evap }}+q_{\text {sens,imp }}+q_{\text {sens,run }}\right) \\
& -\left(q_{\text {kin }}+q_{\text {freeze }}\right)=0 \\
& z=h+B+h_{\text {surf }}
\end{aligned}
$$

where the terms are as defined previously (using a surface temperature of $T_{f}$ ), and $q_{\text {freeze }}=L_{f} \dot{m}_{f}$. Equation (32) may be solved directly for $q_{\text {freeze }}$ and hence $\dot{m}_{f}$.

\section{Substrate Temperature Model}

The substrate temperature may adopt a fixed value or be timedependent. This in turn dictates if (and when) an ice layer will form above the initial water layer. For example, a substrate that holds a temperature of $10{ }^{\circ} \mathrm{C}$ for all time will form an ice layer less quickly than a substrate with a temperature decaying over time. In a complete system, an integrated finite element code would allow two way thermal coupling between the substrate and accretion. This comes at the expense of a higher computational cost. Faster solutions with an acceptable degree of accuracy may be attained by imposition of one of a number of temperature responses. Three such options might be:

1. A 'thin shell' model. In this scenario, the substrate is assumed to be of negligible thickness, high thermal conductivity, and thermally insulated from its underlying supports or mountings. The substrate is assumed to instantaneously adopt the flow total wet bulb temperature [18].

2. A 'thick substrate' model. In this scenario, the substrate is Page 5 of 11 that the substrate has thermally soaked in dry flow and thus is isothermal, with the temperature taken to be the recovery temperature of the flow $T_{r, d r y}$, where

$$
T_{r, d r y}=T_{s}\left(1+r_{f} \frac{\gamma_{f}-1}{2} M_{\infty}^{2}\right)
$$

where $r$ is the recovery factor, $T_{s}$ is the static temperature and $M_{\infty}$ is the freestream Mach number.

3. If matching the model outputs to experimental data, timeresolved substrate temperature data may be available to impose as a boundary condition. This is referred to as the 'experimental boundary condition' model.

Future development could involve coupling EMM-C to a simple finite volume code, such that the substrate temperature response may be predicted rather than prescribed.

\section{Results}

\section{Ice Growth at a Stagnation Point}

The results in this section are intended to be indicative of the capability of the EMM-C model. Validation against experimental data is presented in the ensuing section.

A simple test case of ice building at a stagnation region is considered. To isolate the role of the EMM-C in determining accretion growth rate, ice erosion is not considered and an ice particle sticking probability of unity is assumed, regardless of test condition. The ice and water thicknesses are therefore determined solely by the continuity and energy equations.

The baseline aerodynamic and icing conditions used in the simulations are given in Table 1. Differing values of melt ratio, relative humidity, Mach number were also tested. The effect of implementing the three different substrate temperature response models was also assessed.

Table 1 Parameters used in initial simulations with EMM-C

\begin{tabular}{cc}
\hline \hline Parameter & Baseline value \\
\hline$M[-]$ & 0.40 \\
$T_{0}[\mathrm{~K}]$ & 283 \\
$P_{0}[\mathrm{kPa}]$ & 34.5 \\
$T W C\left[\mathrm{~g} / \mathrm{m}^{3}\right]$ & 8.0 \\
$R H_{0}[-]$ & 0.45 \\
Average melt ratio, $M R[-]$ & 0.2 \\
Initial substrate temperature $[\mathrm{K}]$ & 283 \\
\hline \hline
\end{tabular}

At the baseline conditions, the wet bulb temperature based on total conditions, $T w b_{0}=275.5 \mathrm{~K}$, and the dry recovery temperature is taken as $T_{r, d r y}=282 \mathrm{~K}$. It is assumed that the impinging particles are in the process of melting and thus have uniform temperature $T_{f}$.

\section{Effect of Substrate Temperature Response}

Fig. 7 shows a normalised prediction of internal water layer thickness, $h$, and ice thickness, $B$, for

(i) the 'thin shell' model $\left(T_{\text {subs }}(t)=T w b_{0}=275.5 \mathrm{~K}\right)$;

(ii) the 'thick shell' model $\left(T_{\text {subs }}(t)=T_{r, \text { dry }}=282 \mathrm{~K}\right)$;

(iii) a 'cold' substrate, with a constant temperature of $T_{\text {subs }}(t)=263 \mathrm{~K}$. 
For simplicity the top water film is not shown. In cases (i) and (ii), a water film exists on the substrate for approximately the first $0.5 \mathrm{~s}$, followed by the initiation of a surface ice layer. The then trapped internal film grows due to conduction through it from the warm substrate. For the thick shell model, the predicted height of the internal water layer is approximately double that of the thin shell model after $10 \mathrm{~s}$. The 'cold' substrate case correctly predicts no internal water layer.

The predicted temperature at the exposed accretion surface is plotted in Fig. 8 for the first three seconds of exposure, for the thin shell substrate model and the isothermal cold substrate model. For the former case, the surface of the water layer cools to freezing temperature within the first $\sim 0.6 \mathrm{~s}$; in the latter case a water film may form over the ice layer after $\sim 2 \mathrm{~s}$.

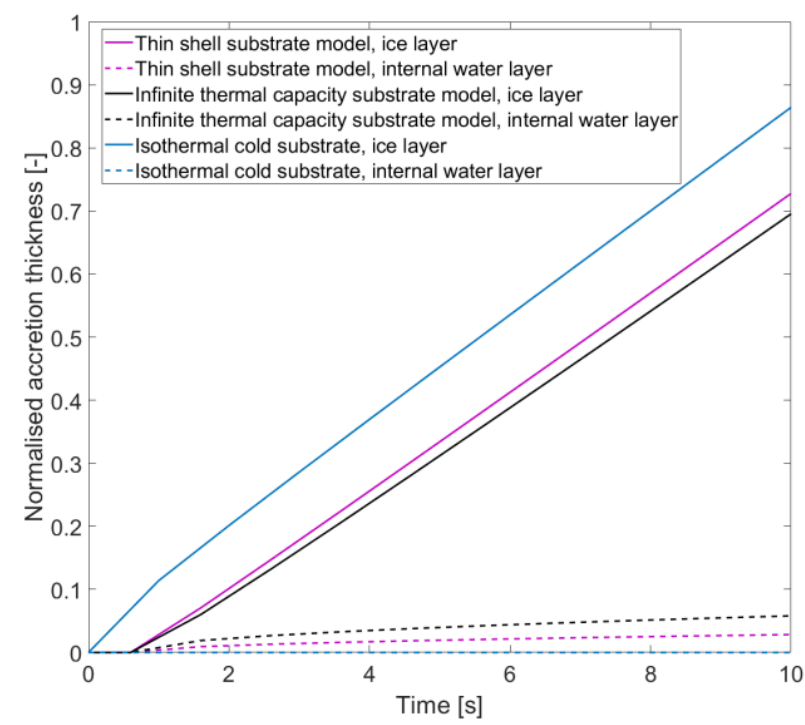

Fig. 7 Predicted thickness of ice and internal water layers for the thin shell and thick shell substrate models, as well as an isothermal 'cold' substrate case

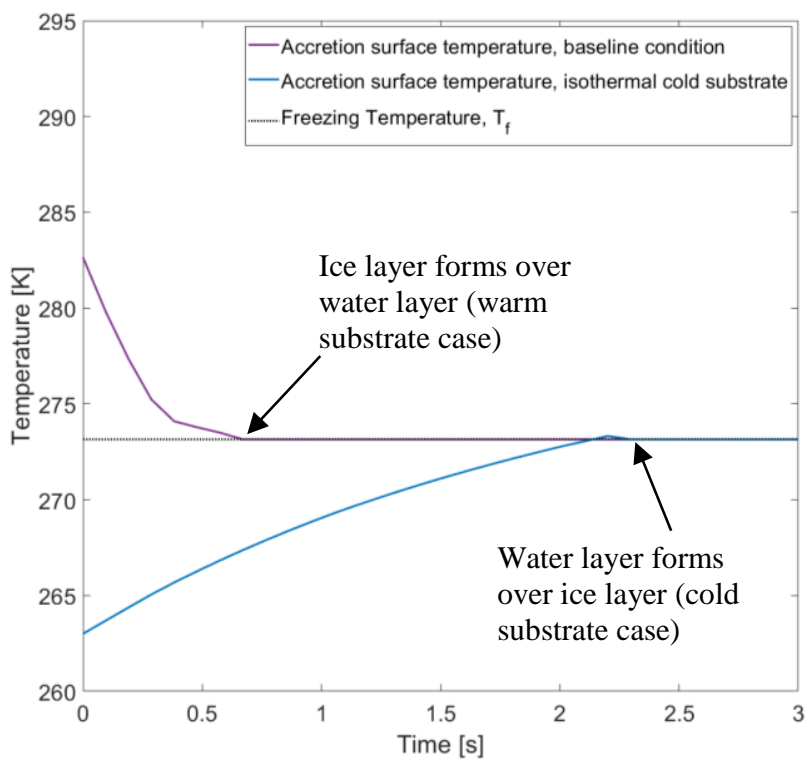

Fig. 8 Predicted temperature of the accretion surface over time for the baseline condition and cold substrate cases

Fig. 9 shows the constituent heat flux terms in the EMM-C model over the first five seconds of exposure, for the baseline condition. Heat fluxes at the exposed water surface comprise convection $\left(q_{\text {conv }}\right)$, sensible warming of runback water $\left(q_{\text {sens,run }}\right)$, sensible warming of impinging particles $\left(q_{\text {sens,imp }}\right)$, evaporation $\left(q_{\text {evap }}\right)$, kinetic heating $\left(q_{\text {kin }}\right)$ and freezing $\left(q_{\text {freeze }}\right)$. These terms are summed to attain the net heat flux at the surface, $q_{\text {surf,net }}$, which is given by equation (32). Finally, the heat flux in the internal water layer, $q_{c o n d, w}$, is calculated. This is the heat conducted from the substrate to the water-ice interface, balanced by the rate of melting at the interface.

There is a positive peak in $q_{\text {net }}$ during the water-only stage (the first $\sim 0.6 \mathrm{~s})$. This signifies net heat transfer away from the exposed surface, driven by the heat flux required to melt the impinging ice particles. There is a constant heat source to the surface due to kinetic energy transfer. The remaining heat flux terms vary as the water surface temperature decreases towards the freezing temperature, $T_{f}$. The convective and evaporative heat flux terms are negative, signifying heat and mass transfer to the water surface respectively. The sensible warming of run-in water $\left(q_{\text {run }}\right)$ is zero for all time since it is assumed that there can be no run-in water for a panel at a stagnation point (tip or leading edge).

Once the exposed surface reaches freezing temperature, assumption (A6) requires that $q_{\text {surf,net }}=0$ and the surface heat flux terms adopt their steady values. The steady freezing heat flux, $q_{\text {freeze }}$, at the exposed surface remains negative, showing that there is sufficient heat to the surface to continue melting impinging ice. The heat conducted in the internal water layer, $q_{c o n d, w}$, does not reach a steady value over the exposure time. It is given by

$$
q_{\text {cond }, w}=-k_{w} \frac{T_{f}-T_{\text {subs }}}{h}=L_{f} \rho_{w} \frac{d h}{d t}
$$

The temperature gradient and hence rate of melting therefore decreases as the layer thickens.

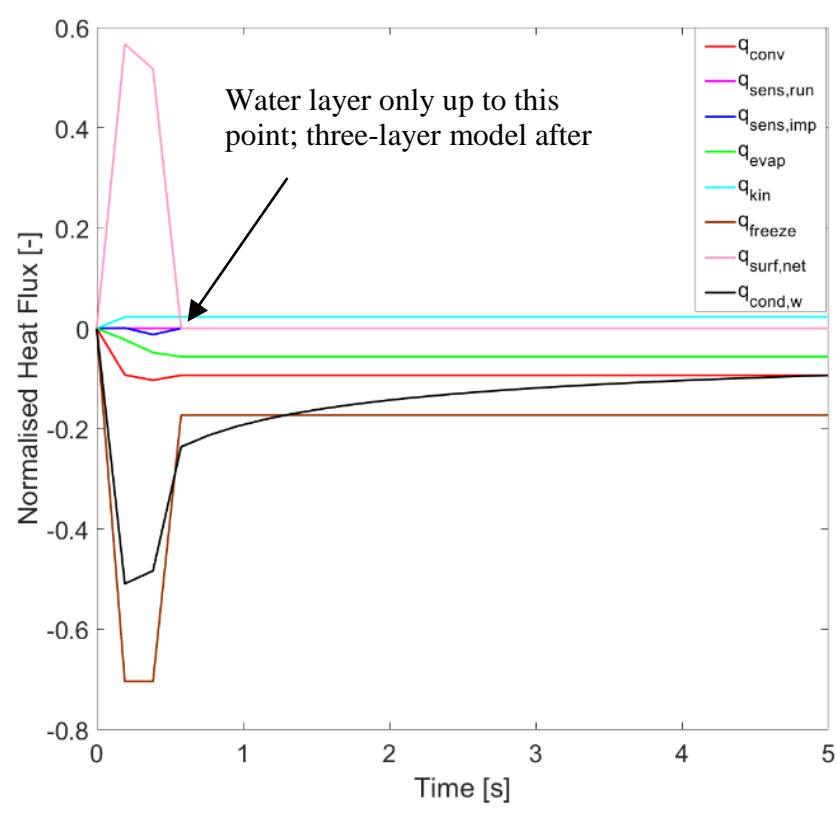

Fig. 9 Constituent heat fluxes in EMM-C for the baseline case

Fig. 10 shows predicted accretion thickness for cases where Mach number and relative humidity were each perturbed in turn. Data are normalised on the same scale as Fig. 7. The case of a reduced Mach number of 0.25 (with the baseline relative humidity), and the case of an increased relative humidity of 0.65 (with the baseline Mach number) are considered. The accretion thicknesses for the baseline condition are once again plotted. In the case of the Mach 0.25 case, the TWC is increased to hold the mass fluxes of ice and water constant.

The primary effect of the reduced Mach number is a reduction in heat flux to the accretion surface. This is due in part to the slowermoving particles reducing the kinetic energy transfer, $q_{k i n}$, but

Page 6 of 11 
primarily due to the reduction in convective and evaporative heat flux to the surface due to the reduction in heat transfer coefficient. These effects result in a reduced melting mass flux and reduced water runback mass flux; hence a greater ice thickness than the baseline case. This illustrates that a significant difference in accretion thickness may be obtained solely by differing thermodynamic conditions, and demonstrates that icing codes cannot rely alone on a continuity-based model (sticking probability, erosion) to produce realistic overall ice profiles.

When the relative humidity is increased from it baseline value of 0.45 to 0.65 , the total wet bulb temperature rises to $5.5{ }^{\circ} \mathrm{C}$. The substrate therefore remains warmer for longer, resulting in a thickened internal water layer. This agrees qualitatively with experiments at the same test conditions [19], where accretions generated at a relative humidity of 0.65 were more translucent (indicative of a water layer on the test article surface) and prone to sliding and shedding. The internal water height could potentially therefore be used to develop or test future shedding models.

For simplicity, it is assumed that the elevated wet bulb temperature does not increase the rate of particle melting, so the average melt ratio is held constant. The evaporative heat flux to the surface increases, due to the increased freestream vapour pressure. This is balanced by an increase in the melting mass flux at the surface, thus generating a higher runback mass flux. The ice thickness is therefore less than half its value in the baseline case.

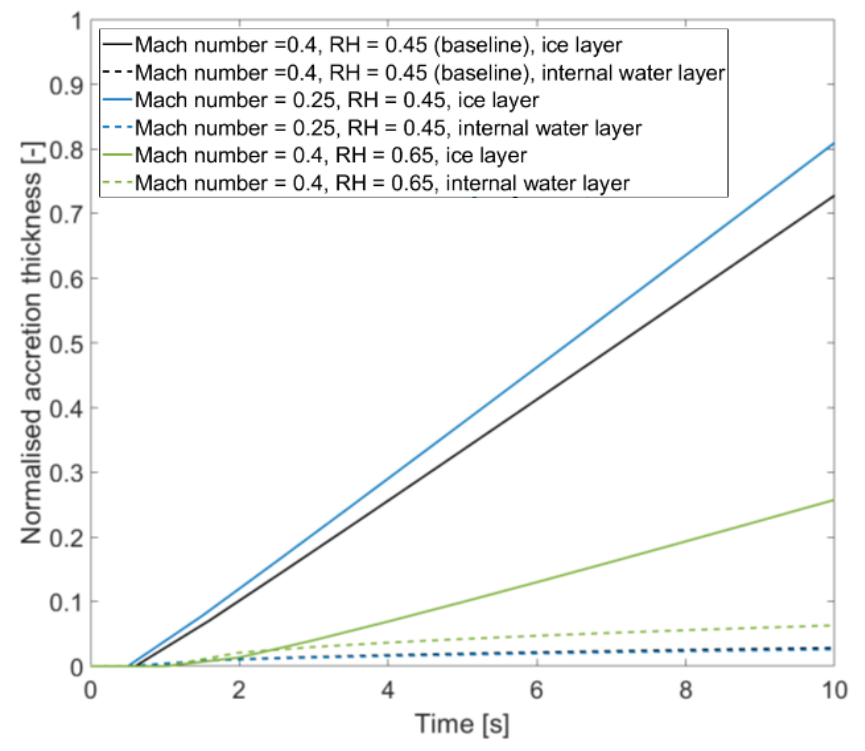

Fig. 10 Predicted accretion thicknesses for perturbed Mach number and relative humidity. Data are plotted for the baseline case $(\mathrm{M}=0.4, \mathrm{RH}=$ 0.45 ), for a case with $\mathrm{M}=0.25$ and for a case with $\mathrm{RH}=0.65$

\section{Validation results}

Ice growth predictions are now shown with comparison to experiments conducted at the Research Altitude Test Facility (RATFac) at the National Research Council of Canada (NRC). Experiments were conducted using a conical test article, with ice growing on three cone 'noses' of $20^{\circ}, 35^{\circ}$ and $45^{\circ}$ half-angle. Details of the test article, test conditions, uncertainty analysis and results may be found in [19]. The baseline icing and aerodynamic conditions were the same as those given in Table 1 . The nominal particle $D_{v, 10}, D_{v, 50}$ and $D_{v, 90}$ were $18 \mu \mathrm{m}, 34 \mu \mathrm{m}$ and $54 \mu \mathrm{m}$ respectively. In keeping with the test article design of a titanium shell bonded to a thick copper substrate, the infinite thermal capacity model was used in the simulations.

Results are shown here for the ice growth at the stagnation point (cone tip). The predicted ice growth is generated from ICICLE, a new computational tool for ice crystal icing. This code features Lagrangian particle tracking and phase change, semi-empirical sticking and erosion models and the EMM-C model. Further detail - and more results of model validation - may be found in [20].

As an additional comparison, the classical Messinger Model [5] has been adapted to glaciated and mixed phase conditions (termed here MM-C). This simply adds the additional heat source and sink terms attributed to ice particles to the steady state heat balance. The substrate is assumed to instantaneously adopt the steady-state icing accretion temperature, $T_{a c c}$. Temperature gradients normal to the wall are therefore neglected. The accretion may be termed 'rime' (i.e. no surface water film, $T_{a c c}<T_{f}$ ), 'glaze' (i.e. with a running surface water film, $T_{a c c}=T_{f}$ ), or running wet (no accretion, $T_{a c c}>$ $T_{f}$ ). The calculation follows the algorithm of Villedieu et al. [21], following Wright et al. [3]. The remainder of the ice crystal icing code (including the erosion model) is run inside ICICLE and hence is no different from the EMM-C predictions.

Fig. 11 shows a comparison of EMM-C and MM-C predictions against experimental measurements of accretion height at the baseline aerodynamic and icing conditions. The MM-C code predicts glaze ice as the steady solution. To aid clarity in the figure, the surface water film is not shown in either the MM-C or EMM-C predictions - it is already taken to arbitrarily thin in accordance with assumption (A6).

For the EMM-C, the ice and internal water layer heights are shown (black and blue lines respectively). Two differing predictions are given. It is important to note that the difference only applies during the initial water film-only stage; in the subsequent three-layer stage the calculations are the same. Firstly (in dash lines), a prediction using the equations presented above. This assumes (in equation 17) that all of the ice mass that 'sticks' to the panel during the water film-only stage (i.e. neglecting the ice that bounces) is entirely melted on impact. This may be seen in Fig. 9 to be the single largest contributor to the net heat flux in this stage. The assumption therefore neglects the possibility that ice particles may remain partially solid and slide or become entrained in the running water film. In the second prediction (in solid lines), a melt fraction of $45 \%$ is chosen to get best agreement between the model and experiment. A partial melt fraction is qualitatively in agreement with work conducted in [22] where it was found that a melt fraction of 30-40\% was obtained for glaciated particles impacting on a clean, warm surface - albeit at a lower TWC and higher wall temperature. It is worth noting that normalised ice thicknesses of less than 0.05 could not be measured accurately in the experiment - and so the exact time at which ice started to form (at around 4-5 s) is not known accurately. Other mechanisms - for example a poorly predicted bouncing mass flux - could also account for the discrepancy in the timing of the water film-only stage. 


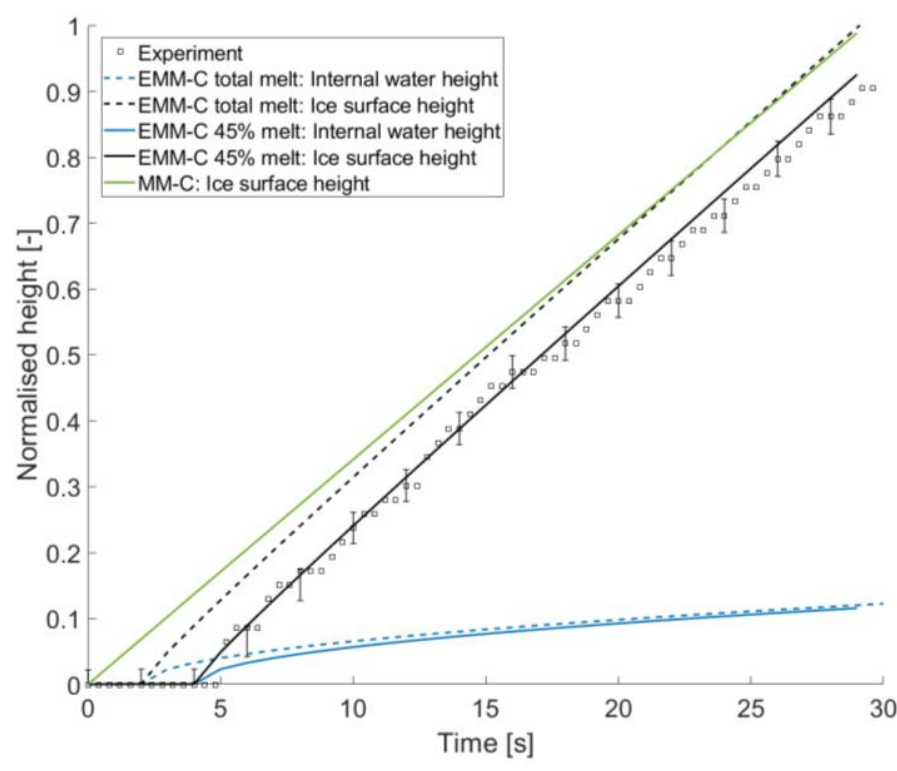

Fig. 11 Comparison of EMM-C and MM-C models for ice growth at the tip of a cone tested in RATFac. Predictions are shown for both total melt of impinging particles when the substrate is clean, and partial melt.

The MM-C prediction of glaze ice is at least in qualitative agreement with the EMM-C, which predicts a three-layer accretion after around $1 \mathrm{~s}$ in the 'total melt' case, increasing to around $4 \mathrm{~s}$ in the $45 \%$ melt case. Once the three-layer accretion is established, the surface energy balance is equal between the EMM-C and MM-C models. In this stage, the mass fraction of impinging particles that melt or freeze is calculated according to equation (32). Hence, the freezing mass flux, $\dot{m}_{f}$, the runback mass flux $\dot{m}_{\text {run,w }}$ and the surface ice growth, $\Delta B_{\text {surf }}$ are matched between the EMM-C and MM-C. However, as may be seen in Fig. 11, this does not necessarily require the ice growth rates (gradient of the solid black and green lines) to be equal. Equation (28) states that the overall ice growth in the three-layer model is the sum of the surface growth, $\Delta B_{\text {surf }}$, and the growth at the interface with the internal water layer, $\Delta B_{\text {int }}$. The latter is timedependent, as shown by the internal water layer height in Fig. 11. Since the density of (pure) ice is $92 \%$ of water, the melting of a given thickness of ice at the internal interface will result in a smaller thickness of water being generated, effectively moving the entire ice layer downwards. This results in the differing gradients of the EMM$\mathrm{C}$ and MM-C models. The gradients will converge on the same value as the rate of melting at the internal interface converges on zero.

Table 2 shows a comparison of normalised accretion heights predicted by MM-C and EMM-C against experimental results. In all cases the partial melt correction is not applied. Comparisons are shown at three relative humidities, including the 0.45 case shown in Fig. 11. With the exception of this case, EMM-C generally performs better than MM-C, generally caused by a better matching of the gradient (growth rate) with experiment. If a suitable model were to be defined to estimate the partial melt in the water film-only stage (as opposed to choosing a value), the agreement could be substantially improved.

Table 2 Comparison of predicted accretion heights by MM-C and EMM-C against experiments with three different relative humidities

\begin{tabular}{cccc}
\hline \hline & \multirow{2}{*}{$\begin{array}{c}\text { Normalised tip } \\
\text { accretion after } \\
\text { 30 s, }\end{array}$} & Error to experiment, \% \\
\cline { 3 - 4 }$R H_{0}[-]$ & $\begin{array}{c}\text { Experiment [-] } \\
\text { exy-C }\end{array}$ & MM-C \\
\hline 0.15 & 0.28 & 6 & 16 \\
0.45 & 0.90 & 10 & 10 \\
0.30 & 0.50 & 8 & 13 \\
\hline \hline
\end{tabular}

\section{Conclusions}

A new thermodynamic model for ice crystal icing has been developed by adapting the Extended Messinger Model to mixed phase conditions and developing a novel three-layer ice crystal accretion structure.

The water-ice-water layer structure makes the model directly applicable to aircraft engine ice crystal icing - where surfaces may initially be significantly above $0{ }^{\circ} \mathrm{C}-$ in comparison to the classical Messinger and Extended Messinger Models, which are strictly valid for the supercooled water icing phenomenon.

The model was presented and predictions given for the case of ice growth at a stagnation point for a range of aerodynamic and icing conditions, as well as three distinct models for the thermal response of the underlying substrate. Finally, a predicted accretion growth history was compared to experimental data from a previous test at the NRC RATFac facility. The new model was shown to compare favourably at matching growth rate compared to the standard Messinger Model, especially near the test start where only a water film exists.

\section{Contact Information}

Corresponding author: Alexander Bucknell

Department of Engineering Science, Oxford Thermofluids Institute alexander.bucknell@eng.ox.ac.uk

\section{Acknowledgments}

The authors would like to thank Rolls-Royce Plc for funding the research and the UK Engineering and Physical Sciences Research Council (EPSRC) for the Centre for Doctoral Training (CDT) in Gas Turbine Aerodynamics studentship (grant ref. EP/L015943/1).

\section{Appendix A - Derivation of Evaporative Heat Flux}

The evaporative heat flux from the accretion surface is given by

$$
\begin{aligned}
q_{\text {evap }}=L_{v} \dot{m}_{\text {evap }} & =L_{v} H_{m} \rho_{f}\left(\omega_{\text {surf }}-\omega_{\infty}\right) \\
& =\frac{L_{v}}{L} \operatorname{Sh} \rho_{f} D_{v, a}\left(\omega_{\text {surf }}-\omega_{\infty}\right)
\end{aligned}
$$

where $H_{m}$ is the average mass transfer coefficient, $L$ is a local lengthscale, $S h$ is the average Sherwood number, $D_{v, a}$ is the diffusivity of vapour in air, and $\omega_{\text {surf }}$ and $\omega_{\infty}$ are the humidity ratios at the surface and in the freestream respectively. Sublimation heat flux may be calculated by replacing $L_{v}$ with $L_{v}+L_{f}$. The vapour diffusivity is given by

$$
D_{v, a}=D_{0}\left(\frac{P_{r e f}}{P_{e}}\right)\left(\frac{T_{e}}{T_{r e f}}\right)^{1.81}
$$

where $D_{0}=22.6 \times 10^{-6} \mathrm{~m} / \mathrm{s}^{2}, P_{\text {ref }}=101.3 \mathrm{kPa}, T_{\text {ref }}=273.15 \mathrm{~K}$, and $P_{e}$ and $T_{e}$ are the local static pressure and temperature at the edge of the boundary layer respectively [23].

A Chilton-Colburn heat-mass transfer analogy is used to express Sherwood number in terms of the previously-calculated heat transfer coefficient (or its non-dimensional form, Nusselt number). This is ratio is described by the analogy factor, $J$ :

$$
J=\frac{N u}{S h}=\left(\frac{P r}{S c}\right)^{b}=L e^{b}
$$


The Lewis number exponent, $b$, is taken as 0.333 in laminar flow [24] and 0.65 for turbulent flow [25]. Hence

$$
S h=N u\left(\frac{P r}{S c}\right)^{-b}=N u L e^{b}=\frac{H L}{k_{f}} L e^{b}
$$

Substituting (A4) into (A1) yields

$$
q_{\text {evap }}=L_{v} L e^{b} \frac{H}{k_{f}} \rho_{f} D_{v a}\left(\omega_{\text {surf }}-\omega_{\infty}\right)
$$

and noting that $\rho_{a} D_{v a} / k_{f}=1 /$ Le $C_{p, a}$ equation (A5) may be written:

$$
q_{\text {evap }}=\frac{L_{v} H}{C_{p, a} L e^{(1-b)}}\left(\omega_{\text {surf }}-\omega_{\infty}\right)
$$

Applying Dalton's law of partial pressures,

$$
\omega=\frac{m_{\text {vap }}}{m_{\text {dry air }}}=\frac{M_{w}}{M_{a}} \frac{P_{\text {vap }}}{P_{0}-P_{\text {vap }}} \cong \frac{M_{w}}{M_{a}} \frac{P_{\text {vap }}}{P_{0}}
$$

hence

$$
q_{\text {evap }} \cong \frac{L_{v} H}{P_{0} C_{p, a} L e^{(1-b)}} \frac{M_{w}}{M_{a}}\left(P_{\text {vap }, \text { surf }}-P_{\text {vap }, \infty}\right)
$$

and $P_{v a p, \infty}=R H_{\infty} P_{v a p, s a t, \infty}$, where $R H_{\infty}$ is the freestream relative humidity and $P_{\text {vap sat, } \infty}$ is the freestream saturation vapour pressure. $P_{\text {vap,surf }}$ is the saturation vapour pressure at the accretion surface. It then remains to calculate these two saturation vapour pressures. A method is described in Appendix B.

The methodology presented here for calculating the evaporative heat flux is used in several existing icing codes [6], [10] and seems to offer sufficiently accurate results for aircraft wing icing, as assessed by comparison between predicted and measured ice shapes. For the foreseeable future, approaches such as this will be transferred into ice crystal icing codes, due to their inherent simplicity and the complexity of modelling mass transfer within a turbomachinery environment. It is therefore important to bear in mind the limitations inherent in the derivation. The analogy factors are applicable to turbine aerofoils (thin boundary layers) rather than compressor aerofoils. The assumption of two-dimensional flow may be applicable at midspan for high aspect ratio blades, but will not be near endwalls where secondary flows and corner separations dominate; and the assumption of uniform wall temperature is unlikely to hold once icing is initiated. There is therefore significant work ahead to improve model applicability.

\section{Appendix B - Saturation Vapour Pressure}

Table B1 gives the gradients and y-intercepts of the 19-segment piecewise linear fit of saturation vapour pressure, valid for temperatures in the range $245-320 \mathrm{~K}$.

Table B1 - Gradients and y-intercepts of piecewise fit for $P_{\text {vap }, \text { sat }}$

\begin{tabular}{cccc}
\hline \hline Segment & Lower T bound & Gradient, $E_{m}$ & Intercept, $E_{c}$ \\
\hline 1 & 245.0 & 5.698 & $-1.3500 \mathrm{E} 3$ \\
2 & 249.0 & 8.231 & $-1.9820 \mathrm{E} 3$ \\
3 & 253.1 & 11.74 & $-2.8710 \mathrm{E} 3$ \\
4 & 257.1 & 16.56 & $-4.1120 \mathrm{E} 3$ \\
\hline \hline
\end{tabular}

Page 9 of 11

\begin{tabular}{cccc}
\hline \hline 5 & 261.1 & 23.110 & $-5.8210 \mathrm{E} 3$ \\
6 & 265.2 & 31.89 & $-8.1510 \mathrm{E} 3$ \\
7 & 269.2 & 43.62 & $-1.1311 \mathrm{E} 4$ \\
8 & 273.3 & 50.96 & $-1.3315 \mathrm{E} 4$ \\
9 & 277.3 & 65.49 & $-1.7344 \mathrm{E} 4$ \\
10 & 281.3 & 83.42 & $-2.2391 \mathrm{E} 4$ \\
11 & 285.4 & 105.4 & $-2.8663 \mathrm{E} 4$ \\
12 & 289.4 & 132.1 & $-3.6396 \mathrm{E} 4$ \\
13 & 293.5 & 164.4 & $-4.5858 \mathrm{E} 4$ \\
14 & 297.5 & 202.9 & $-5.7351 \mathrm{E} 4$ \\
15 & 301.6 & 248.9 & $-7.1218 \mathrm{E} 4$ \\
16 & 305.6 & 303.3 & $-8.7837 \mathrm{E} 4$ \\
17 & 309.6 & 367.2 & $-1.0763 \mathrm{E} 5$ \\
18 & 313.6 & 441.9 & $-1.3106 \mathrm{E} 5$ \\
19 & 317.7 & 528.7 & $-1.5863 \mathrm{E} 5$ \\
\hline \hline
\end{tabular}

The error arising from the new piecewise linear fit is $<1 \%$ across the range specified.

\section{References}

[1] J. G. Mason, J. W. Strapp, and P. Chow, 'The Ice Particle Threat to Engines in Flight', presented at the 44th AIAA Aerospace Sciences Meeting and Exhibit, Reno, Nevada, 2006.

[2] R. W. Gent, 'TRAJICE2: a combined water droplet and ice accretion prediction code for aerofoils', Royal Aircraft Establishment, TR90054, 1994.

[3] W. B. Wright, P. C. E. Jorgenson, and J. P. Veres, 'Mixed Phase Modeling in GlennICE with Application to Engine Icing', presented at the AIAA Atmospheric and Space Environments Conference, Toronto, Ontario Canada, 2010.

[4] T. Currie, D. Fuleki, and A. Mahallati, 'Experimental Studies of Mixed-Phase and Sticking Efficiency for Ice Crystal Accretion in Jet and Engines', presented at the 6th AIAA Atmospheric and Space Environments Conference, Atlanta, GA, 2014.

[5] B. L. Messinger, 'Equilibrium Temperature of an Unheated Icing Surface as a Function of Air Speed', J. Aeronaut. Sci, vol. 120, no. 1, pp. 29-42, Jan. 1953.

[6] R. W. Gent, N. P. Dart, and J. T. Cansdale, 'Aircraft icing', Phil. Trans. R. Soc. Lond, vol. 358, pp. 2873-2911, 2000.

[7] P. Trontin, G. Blanchard, and P. Villedieu, 'A Comprehensive Numerical Model for Mixed Phase and Glaciated Icing Conditions', presented at the 8th AIAA Atmospheric and Space Environments Conference, Washington, D.C., USA, 2016.

[8] P. Trontin and P. Villedieu, 'A Comprehensive Accretion Model for Glaciated Icing Conditions', International Journal of Multiphase Flow, vol. 108, pp. 105-123, Nov. 2018.

[9] R. Chauvin, L. Bennai, P. Trontin, and P. Villedieu, 'An implicit time marching Galerkin method for the simulation of icing phenomena with a triple layer model', Finite Elements in Analysis and Design, vol. 150, pp. 20-33, 2018.

[10] T. G. Myers, 'Extension to the Messinger Model for Aircraft Icing', AIAA J., vol. 39, no. 2, pp. 211-218, Feb. 2001.

[11] S. Ozgen and M. Canibek, 'Ice Accretion Simulation on Multi-Element Airfoils Using Extended Messinger Model', Heat Mass Transf, vol. 45, pp. 305-322, Jul. 2008.

[12] C. Califf and D. Knezevici, 'Use of a Turbofan Engine to Measure Ice Crystal Cloud Concentration In-Flight', presented at the 50th AIAA/ASME/SAE/ASEE Joint Propulsion Conference, Cleveland, OH, USA, 2014. 
[13] T. Bartkus, P. M. Struk, and J. Tsao, 'Development of a Coupled Air and Particle Thermal Model for Engine Icing Test Facilities', presented at the SAE International Conference on Icing of Aircraft, Engines and Structures, Prague, CZ, 2015.

[14] E. Ayan and S. Ozgen, 'In-Flight Ice Accretion Simulation in Mixed Phase Conditions', The Aeronautical Journal, vol. 122, no. 1249 , pp. 409-441, Mar. 2018.

[15] E. Ayan and S. Ozgen, 'Modification of the Extended Messinger Model for Mixed Phase Icing and Industrial Applications with TAICE', presented at the 9th AIAA Atmospheric and Space Environments Conference, Denver, CO, USA, 2017.

[16] P. M. Struk, T. Bartkus, and Tsao J., 'Ice Accretion Measurements on an Airfoil and Wedge in Mixed-Phase Conditions', SAE Technical Paper 2015-01-2116, 2015.

[17] R. W. Hyland and A. Wexler, 'Formulations for the thermodynamic properties of dry air from $173.15 \mathrm{~K}$ to $473.15 \mathrm{~K}$, and of saturated moist air from $173.15 \mathrm{~K}$ to $372.15 \mathrm{~K}$, at pressures to $5 \mathrm{MPa}$ ', ASHRAE Transactions, 1983.

[18] P. M. Struk et al., 'Fundamental Ice Crystal Accretion Physics Studies', presented at the SAE 2011 International Conference on Aircraft and Engine Icing and Ground Deicing, Chicago, IL, USA, 2011.

[19] A. Bucknell, M. McGilvray, D. R. H. Gillespie, G. Jones, A. Reed, and B. Collier, 'Experimental Studies of Ice Crystal Accretion on an Axisymmetric Body at Engine-Realistic Conditions', presented at the 2018 Atmospheric and Space Environments Conference, Atlanta, GA, USA, 2018.

[20] A. Bucknell, M. McGilvray, D. R. H. Gillespie, G. Jones, and B. Collier, 'A Model for Glaciated \& Mixed Phase Icing for Application to Aircraft Engines', presented at the International Conference on Icing of Aircraft, Engines, and Structures, Minneapolis, MN, 2019.

[21] P. Villedieu, P. Trontin, and R. Chauvin, 'Glaciated and mixed-phase ice accretion modeling using ONERA 2D icing suite', presented at the 6th AIAA Atmospheric and Space Environments Conference, Atlanta, GA, 2014.

[22] A. Bucknell, M. McGilvray, D. R. H. Gillespie, G. Jones, A. Reed, and D. R. Buttsworth, 'Heat Transfer in the Core Compressor Under Ice Crystal Icing Conditions', Journal of Engineering for Gas Turbines and Power, vol. 140, pp. 071501 1-13, Jul. 2018.

[23] T. Hauk, E. Bonaccurso, P. Villedieu, and P. Trontin, 'Theoretical and Experimental Investigation of the Melting Process of Ice Particles', Journal of Thermophysics and Heat Transfer, vol. 30, no. 4, pp. 946-954, 2016.

[24] E. R. G. Eckert, H. Sakamato, and T. W. Simon, 'The heat/mass transfer analogy factor, $\mathrm{Nu} / \mathrm{Sh}$, for boundary layers on turbine blade profiles', International Journal of Heat and Mass Transfer, vol. 44, pp. 1223-1233, 2001.

[25] M. Häring and B. Weigand, 'A New Analogy Function For The Naphthalene Sublimation Technique To Measure Heat Transfer Coefficients on Turbine Aerofoils', presented at the International Gas Turbine and Aeroengine Congress and Exposition, Houston, TX, USA, 1995.

\begin{tabular}{|c|c|c|}
\hline \multicolumn{3}{|l|}{ Latin } \\
\hline$b$ & Lewis number exponent & - \\
\hline$B$ & Ice thickness & $\mathrm{m}$ \\
\hline $\mathrm{C}_{1}$ & Evaporation constant & $\mathrm{m} / \mathrm{s}$ \\
\hline $\mathrm{C}_{\mathrm{p}}$ & $\begin{array}{l}\text { Specific heat capacity at constant } \\
\text { pressure }\end{array}$ & $\mathrm{J} /(\mathrm{kg} . \mathrm{K})$ \\
\hline $\mathrm{D}_{\mathrm{va}}$ & $\begin{array}{l}\text { Diffusion coefficient of water } \\
\text { vapour in air }\end{array}$ & $\mathrm{m}^{2} / \mathrm{s}$ \\
\hline $\mathrm{D}_{\mathrm{v}, \mathrm{xx}}$ & $\begin{array}{l}\text { Diameter for which all particles with } \\
D<D_{v, x x} \text { constitute } x x \% \text { of the total } \\
\text { volume }\end{array}$ & $\mu \mathrm{m}$ \\
\hline $\mathrm{E}_{\mathrm{m}}, \mathrm{E}_{\mathrm{c}}$ & $\begin{array}{l}\text { Gradient and y-intercept of } \\
\text { saturation vapour pressure fit }\end{array}$ & $\mathrm{Pa} / \mathrm{K}, \mathrm{Pa}$ \\
\hline $\operatorname{EMM}(-\mathrm{C})$ & $\begin{array}{l}\text { Extended Messinger Model (adapted } \\
\text { to ice crystal icing) }\end{array}$ & \\
\hline $\mathrm{h}$ & Water thickness & $\mathrm{m}$ \\
\hline $\mathrm{H}$ & Heat transfer coefficient & $\mathrm{W} /\left(\mathrm{m}^{2} \cdot \mathrm{K}\right)$ \\
\hline $\mathrm{H}_{\mathrm{m}}$ & Mass transfer coefficient & $\mathrm{m} / \mathrm{s}$ \\
\hline$\dot{\mathrm{h}}$ & Ice growth rate & $\mathrm{m} / \mathrm{s}$ \\
\hline$J$ & Chilton-Colburn analogy factor & - \\
\hline $\mathrm{k}$ & Thermal conductivity & $\mathrm{W} /(\mathrm{m} \cdot \mathrm{K})$ \\
\hline $\mathrm{L}$ & Characteristic length & $\mathrm{m}$ \\
\hline $\mathrm{L}_{\mathrm{f}}$ & Latent heat of fusion & $\mathrm{J} / \mathrm{kg}$ \\
\hline $\mathrm{L}_{\mathrm{s}}$ & Latent heat of sublimation $=\mathrm{L}_{\mathrm{f}}+\mathrm{L}_{\mathrm{v}}$ & $\mathrm{J} / \mathrm{kg}$ \\
\hline $\mathrm{L}_{\mathrm{V}}$ & Latent heat of vaporisation & $\mathrm{J} / \mathrm{kg}$ \\
\hline$\dot{\mathrm{m}}$ & Mass flux & $\mathrm{kg} /\left(\mathrm{s} \cdot \mathrm{m}^{2}\right)$ \\
\hline $\mathrm{m}$ & Mass & $\mathrm{kg}$ \\
\hline M & Molecular mass & $\mathrm{kg} / \mathrm{mol}$ \\
\hline $\mathrm{MM}(-\mathrm{C})$ & $\begin{array}{l}\text { Messinger Model (adapted to ice } \\
\text { crystal icing) }\end{array}$ & \\
\hline$\dot{\mathrm{n}}$ & Molar flux & $\mathrm{mol} / \mathrm{s}$ \\
\hline $\mathrm{P}$ & Pressure & $\mathrm{Pa}$ \\
\hline$q$ & Heat flux per unit area & $\mathrm{W} / \mathrm{m}^{2}$ \\
\hline $\mathrm{r}_{\mathrm{f}}$ & Recovery factor & - \\
\hline $\mathrm{R}_{\mathrm{f}}$ & Specific gas constant of air & $\mathrm{J} /(\mathrm{kg} \cdot \mathrm{K})$ \\
\hline $\mathrm{RH}$ & Relative humidity & - \\
\hline $\mathrm{t}$ & Time & $s$ \\
\hline $\mathrm{T}$ & Temperature & $\mathrm{K}$ \\
\hline Twb & Wet bulb temperature & $\mathrm{K}$ \\
\hline $\mathrm{T}_{\mathrm{f}}$ & Freezing temperature of water & $\mathrm{K}$ \\
\hline $\mathrm{U}$ & Velocity & $\mathrm{m} / \mathrm{s}$ \\
\hline$Z$ & Wall-normal distance & $\mathrm{m}$ \\
\hline Greek & & \\
\hline$\alpha$ & Thermal diffusivity $=\mathrm{k}_{\mathrm{f}} / \rho \mathrm{C}_{\mathrm{p}}$ & $\mathrm{m}^{2} / \mathrm{s}$ \\
\hline$\beta$ & Collection efficiency & - \\
\hline$\gamma_{\mathrm{f}}$ & Isentropic exponent of air & - \\
\hline$\Delta$ & Increment & - \\
\hline$\mu_{\mathrm{f}}$ & Dynamic viscosity & Pa .s \\
\hline$\rho$ & Density & $\mathrm{kg} / \mathrm{m}^{3}$ \\
\hline$\theta$ & Water temperature & $\mathrm{K}$ \\
\hline$\omega$ & Vapour mass fraction & - \\
\hline
\end{tabular}

\section{Nomenclature}




$\begin{array}{ll}\text { Subscripts } & \\ o & \text { Total } \\ \infty & \text { Freestream } \\ a & \text { Air } \\ \text { acc } & \text { Accretion } \\ B & \text { Top of ice layer } \\ \text { conv, cond } & \text { Convection, conduction } \\ \text { evap } & \text { Evaporation } \\ h & \text { Top of water layer } \\ i & \text { Ice } \\ \text { imp, } & \text { Impinging, sticking }(\text { particles }) \\ \text { stick } & \\ \text { int } & \text { Internal (water) } \\ \text { kin } & \text { Kinetic } \\ \text { loc } & \text { Local } \\ \text { sat } & \text { Saturation } \\ \text { sens } & \text { Sensible warming } \\ \text { sub } & \text { Sublimation } \\ \text { subs } & \text { Substrate } \\ \text { surf } & \text { Surface } \\ t & \text { Timestep t } \\ \text { vap } & \text { Vapour } \\ W & \text { Water } \\ X & \text { Axial direction } \\ Z & \text { Wall-normal direction } \\ \text { Groups } & \\ \text { Le } & \text { Lewis number }=k_{f} / D_{v a} \rho C_{p} \\ \mathrm{M} & \text { Mach number }=U / \sqrt{\gamma_{f} R_{f} T} \\ \mathrm{Nu} & \text { Nusselt number }=H L / k_{f} \\ \mathrm{Pe} & \text { Peclet number }=U L / \alpha \\ \text { Pr } & \text { Prandlt number }=\mu / C_{p} k_{f} \\ \text { Re } & \text { Reynolds number }=\rho U L / \mu_{f} \\ \text { Rep } & \text { Particle Reynolds number }= \\ \text { Sc } & \rho U_{\text {rel }} D_{p} / \mu_{f} \\ \text { Sh } & \text { Schmidt number }=\mu / \rho D_{a v} \\ & \text { Sherwood number }=H_{m} L / D_{a v} \\ & \end{array}$

